\title{
Analysis of adaptation potentials of kick boxers' cardio-vascular system
}

\author{
Podrigalo L.V. ${ }^{1}$, Volodchenko A.A. ${ }^{1}$, Rovnaya O.A. ${ }^{1}$, Ruban L.A. ${ }^{1}$, Sokol K.M. ${ }^{2}$ \\ ${ }^{1}$ Kharkov State Academy of Physical Culture, Kharkov, Ukraine \\ ${ }^{2}$ Kharkov National Medical University, Kharkov, Ukraine
}

\begin{abstract}
Purpose:

Analysis and assessment of athletes' adaptation potential are important components of effective selection and prediction of sports successfulness.

Purpose: study and analysis of kick boxers' cardio-vascular system's adaptation potentials under standard physical load and in recreation.

Material: $\quad$ in the research kick boxers ( $n=17$, students) participated. The athletes were divided into 2 groups, depending on reaction to physical load: 1 st group - athletes with normotonic type of reaction $(n=9$, age $17.56 \pm 0.80$ years); 2 nd group - athletes with reaction different from normotonic ( $n=8$, age $18.25 \pm 0.88$ years). Indicators of cardio-vascular reaction type and tolerance to physical load were found with the help of PWC170 test.

Results: $\quad$ we confirmed similarity of kick boxers' reaction to physical load. After 1st stage of physical load heart beats rate was noticeably lower in the 1st group. After 2 nd stage of load systolic blood pressure was lower in the 1st group. After load, in the 1st group heart beats rate and systolic BP restored quicker. Reduction of heart beats rate under load in 1st group can serve as a proof of better adaptation mechanisms.

Conclusions: training of athletes with periodic control of electric cardiogram under physical loads permits to assess functional state of cardio-vascular system; its adaptation and correspondence to definite physical loads. Such approach permits not to admit progressing of cardio-vascular system's pathological state.

Keywords: $\quad$ kick boxing, cardio-vascular system, adaptation, students, physical load.
\end{abstract}

\section{Introduction}

Analysis and assessment of athletes' adaptation potential are important components of effective selection and prediction of their sport successfulness. DurkalecMichalski et al. [1] confirmed that aerobic potentials of martial arts athletes' are connected with specific weight of somatic type components. It conditions significant influence of these abilities on bio-chemical adaptation and tolerance to physical loads.

Correlation between physiological and physical profiles of young wrestlers was confirmed by Jafari et al. [2]. They offered to use physiological indicators for selection of athletes and determination of their prospects. Similar data were received by Mirzaei et al. [3]. The authors found dependence betweenA aerobic power, somatic type components and trainability of wrestlers.

Podrigalo L.V. et al. [4] studied correlations of morphological functional indicators of martial arts athletes and their influence on sportsmanship. These correlations were higher in athletes with higher sportsmanship. Korobeynikov G.V. et al. [5] found interconnections between high workability and successfulness in sport dances. They proved that mobilization of junior athletes' organism's adaptation resources is followed by growth of sympathetic adrenaline system's activation.

Bakhareva A.S. et al. [6] studied adaptation aspects of ski racers. Metabolic changes of athletes' organisms at optimal level result in working muscles' energy supply improvement; in increase of energetic systems' power and efficiency.

Podrigalo L.V. and Volodchenko A.A. [7] fulfilled

(c) Podrigalo L.V., Volodchenko A.A., Rovnaya O.A.,

Ruban L.A., Sokol K.M., 2017

doi:10.15561/18189172.2017.0407 comparative analysis of bio-mechanical characteristics of different martial kinds' athletes. They found influence of specificity of kind of sports on athletes' functional state, which permitted to raise their adaptation potentials.

Pryshva O.B. [8] confirmed that determination of athletes' adaptation potential and its dynamic shall be considered in trainings' planning and assessment of training effectiveness. The similar results were received also in other works $[9,10]$. These authors note demand in optimization of physical loads for increasing training effectiveness.

It is known that cardio-vascular system is and indicators of adaptation potentials. That is why study of its reaction to loads shall be regarded as a relevant task of sport science. Allen Mark S. et al. [11] confirmed importance of cardio-vascular system's state as illustration of athletes' tolerance to loads. The study of its parameters can be used for prediction. The same results were received in other works [12, 13].

Kotenko K.V. et al. [14] note that all kinds of functional testing in sports are based on analysis of cardiorespiratory system's indicators obtained under significant physical loads.

Pankova N.B. et al. [15] carried out monitoring of cardio-vascular system's reserves in junior figure skaters. They showed that in functional state monitoring analysis of indicators' changes under sub-maximal physical loads, is the most informative.

Perkhurov A.M. [16] notes the presence of correlation between cardiologic control data and athletes' sport efficiency in cyclic kinds of sports. The offered by the author functional index of ECG permits to improve prediction of athletes' competition functioning.

Thus, the available literature data confirm importance 
of cardio-vascular system's study for analysis of martial arts athletes' adaptation potential. Knowledge of mechanisms of development and main properties of physiological sport heart permits to assess functional state of cardio-vascular system, to monitor its state in training process. Correct and rational practicing of physical exercises, considering sportsman's fitness and kind of sports results in positive changes in cardio-vascular system. It happens at the account of economizing of its work and increase of adaptation potential.

The purpose of the present research was study and analysis of kick boxers' cardio-vascular system's adaptation potentials under standard physical load and in recreation.

\section{Material and methods}

Participants: in the research kick boxers $(n=17$, students) participated. The athletes were divided into 2 groups, depending on reaction to physical load: $1^{\text {st }}$ group - athletes with normotonic type of reaction $(n=9$, age $17.56 \pm 0.80$ years); $2^{\text {nd }}$ group - athletes with reaction different from normotonic ( $\mathrm{n}=8$, age $18.25 \pm 0.88$ years).

Design of the research: the research was conducted on the base of Kharkov State Academy of Physical Culture. Indicators of cardio-vascular reaction type and tolerance to physical load were found with the help of $\mathrm{PWC}_{170}$ test. The test was fulfilled on «Kettler» bike ergo meter. We used computer system CardiolabSens (production of производства "KhAI-Medica", Kharkov) with continuous recording of electric cardiogram (ECG). On ergo meter athletes fulfilled two loads. The power of first was $100 \mathrm{~W} / \mathrm{min}$ and the second $-150 \mathrm{~W} / \mathrm{min}$. Every work lasted 3 minutes. Speed of pedals' rotation on ergo meter was 60 rotations per minute. At third minute of every stage of work we registered heart beats rate (HBR) for last 30 seconds. After every minute of rest (during three minutes) we registered HBR. BP was found at the end of every load, without stoppage of pedals' rotation.
Statistical analysis: was fulfilled with the help of licensed Excel electronic tables. We determined the following indicators of descriptive statistic: mean arithmetic, standard deviation and error of mean value. Confidence of differences was assessed with parametric Student's t-test and non parametric Wilcoxon - Manna Whitney test (U) and Wald - Wolfovits $\AA$; difference was considered to be confident at $\mathrm{p}<0.05$.

\section{Results}

The volume of the fulfilled work under first load was $(2346.00 \pm 161.28) \mathrm{kg} / \mathrm{m}$ in first group and $(2409.75 \pm 167.98) \mathrm{kg} / \mathrm{m}$ in second. Difference is insignificant ( $p>0.05)$. After second load results were: $(3111.00 \pm 148.69) \mathrm{kg} / \mathrm{m}$ and $(3155.63 \pm 236.56) \mathrm{kg} / \mathrm{m}$. Difference was also insignificant $(\mathrm{p}>0.05)$.

Results of HBR, systolic BP (SBP) and diastolic BP (DBP) dynamic are presented in table 1 .

The data of table 1 confirm the similarity of athletes' reaction to load. It is also illustrated by the fact that there are no significant differences between most of the studied indicators.

But still, some differences between groups were found. For example Student's t-test confirmed confidently less HBR indicators at $1^{\text {st }}$ stage of loads in athletes with normotonic type of reaction $(\mathrm{t}=2.07, \mathrm{p}<0.05)$. On $2^{\text {nd }}$ stage of load indicators of diastolic blood pressure (DBP) were confidently lower in $2^{\text {nd }}$ group $(t=2.27, p<0.05)$. Non parametrical criteria also confirmed some differences between groups. For example, initial DBP in $1^{\text {st }}$ group was much lower $(\mathrm{U}=14, \mathrm{p}<0.05)$.

After $1^{\text {st }}$ stage of load HBR indicators were significantly lower in $1^{\text {st }}$ group $(U=17, p<0.05)$. After $2^{\text {nd }}$ stage of load systolic blood pressure (SBP) was lower in first group $(U=19, p<0.05)$. DBP indicators in $1^{\text {st }}$ group were higher $(U=12, p<0.05 ; \mathrm{r}=5, \mathrm{p}<0.05)$.

Some differences were found also in dynamic of recreation. In last minute of relaxation SBP was lower in

Table 1. Dynamic of cardio-vascular system's indicators of kick boxers under load and in recreation

\begin{tabular}{|c|c|c|c|c|c|c|}
\hline & \multicolumn{3}{|l|}{1 group } & \multicolumn{3}{|l|}{2 group } \\
\hline & HBR, $\min ^{-1}$ & $\begin{array}{l}\text { SBP, mm } \\
\text { merc.col. }\end{array}$ & $\begin{array}{l}\text { DBP, mm } \\
\text { merc.col. }\end{array}$ & HBR, $\min ^{-1}$ & $\begin{array}{l}\text { SBP, mm } \\
\text { merc.col. }\end{array}$ & $\begin{array}{l}\text { DBP, mm } \\
\text { merc.col. }\end{array}$ \\
\hline \multirow{2}{*}{ Before load } & 80.67 & 110.00 & 69.44 & 79.75 & 110.63 & 72.50 \\
\hline & $\pm 3,24$ & $\pm 3,63$ & $\pm 2,82$ & $\pm 3,36$ & $\pm 4,06$ & $\pm 2,31$ \\
\hline \multirow{2}{*}{1 stage } & 131.44 & 128.33 & 66.67 & 143.75 & 133.13 & 56.25 \\
\hline & $\pm 3,50^{1,2}$ & $\pm 5,40^{2}$ & $\pm 3,33$ & $\pm 4,80^{2}$ & $\pm 13,85$ & $\pm 4,20^{2}$ \\
\hline \multirow{2}{*}{2 stage } & 171.33 & 148.89 & $65.56^{1}$ & 180.00 & 165.63 & 37.50 \\
\hline & $\pm 9,88^{2,3}$ & $\pm 4,84^{2,3}$ & $\pm 8,84$ & $\pm 16,64^{2,3}$ & $\pm 11,40^{3}$ & $\pm 8,61^{3}$ \\
\hline \multirow{2}{*}{1 minute } & 113.11 & 128.33 & 61.11 & 114.14 & 128.57 & 60.00 \\
\hline & $\pm 4,02^{2,3}$ & $\pm 3,54^{2,3}$ & $\pm 3,51$ & $\pm 4,60^{2,3}$ & $\pm 8,36^{2}$ & $\pm 4,88^{2,3}$ \\
\hline \multirow[t]{2}{*}{2 minute } & 103.75 & 120.63 & 70.00 & 108.25 & 122.50 & 60.00 \\
\hline & $\pm 3,61^{3}$ & $\pm 5,55$ & $\pm 3,78$ & $\pm 7,27^{3}$ & $\pm 4,79$ & $\pm 4,08^{3}$ \\
\hline \multirow{2}{*}{3 minute } & 97.38 & 108.88 & 62.50 & 100.67 & 120.00 & 66.67 \\
\hline & $\pm 2,18^{3}$ & $\pm 3,90$ & $\pm 1,64^{3}$ & $\pm 9,06^{3}$ & $\pm 5,77$ & $\pm 3,33$ \\
\hline
\end{tabular}

Note: 1 - difference from group 2 is confident $(p<0.05)$. 2 - difference from previous stage is confident $(p<0.05) .3-$ difference from initial level is confident $(p<0.05)$. 
$1^{\text {st }}$ group $(U=4, p<0.05)$, as well as DBP indicators $(U=2$, $\mathrm{p}<0.05)$.

It was interesting to observe over dynamic of the studied indicators in each group separately. The $1^{\text {st }}$ stage of load in first group was characterized by noticeable increase of HBR and SBP indicators. In $2^{\text {nd }}$ group first stage of load was characterized by increase of HBR and reduction of SBP. In $1^{\text {st }}$ group increase of load power resulted in still higher increment of HBR and SBP indicators. There were substantial differences between them and initial level as well as previous stage of load $(\mathrm{p}<0.05)$. In group 2 all three indicators rather differed from initial level. Comparison with previous stage of load revealed noticeable tachycardia.

The first minute of all athletes' rest was characterized by significant dynamic of indicators. In $1^{\text {st }}$ group it was found: reductions of HBR and SBP in respect to the previous stage; preservation of increased indicators in respect to initial level. In $2^{\text {nd }}$ group HBR and SBS indicators reduced. SBS indicator increased in respect to the previous stage. In respect to initial level HBR was noticeably higher, while DBP - lower $(\mathrm{p}<0.05)$. The second minute of relaxation proved the found tendency in indicators' dynamic in group 1: BP indicators stabilized, HBR indicators were significantly higher in comparison with initial level. In group 2 indicators did not noticeably differ from the values in first minute of relaxation. Comparatively with initial level we confirmed substantial increase of HBR and reduction of SBP.

Finalizing stage of recreation also had its peculiarities. In group $1 \mathrm{SBP}$ practically returned to initial level. DBP was significantly lower than indicators before load and HBR indicators remained to be increased.

In group $2 \mathrm{BP}$ indicators did not differ from initial data and the data of previous stage.

According to commonly accepted approaches ECG analysis was fulfilled by the value of intervals (see table 2).
Application of Student's t-test did not confirm substantial differences between groups. That is why we used non parametrical test of Wilcoxon-Manna-Whitney. With its help we found definite differences between groups. Interval QRS in group 1 after load of $2^{\text {nd }}$ stage was less $(U=20, p<0.05)$. In first minute of recreation interval $P Q$ in the same group was less $(U=13, p<0.05)$. In the last minute of recreation in group 1 interval $\mathrm{P}$ was less $(\mathrm{U}=4$, $\mathrm{p}<0.05)$ as well as interval PQ $(\mathrm{U}=4, \mathrm{p}<0.05)$.

We proved substantial ECG intervals' differences between groups in dynamic of load and recreation. In group 1 substantial changes of interval QT by Student's t-test. Both load stages were characterized by its contraction in respect to initial level (accordingly, $t=3.57$ and $t=3.73, p<0.05)$. The same changes were found in first and third minutes of relaxation (accordingly, $\mathrm{t}=3.03$ and $\mathrm{t}=2.05, \mathrm{p}<0.05$ ). In second minute of relaxation higher error did not permit to confirm differences by Student's criterion. However, criterion of Wilcoxon - MannaWhitney witnessed about less interval $(U=9, \mathrm{p}<0.05)$.

In group 2 the first load resulted in significant reduction of interval $(\mathrm{t}=4.91, \mathrm{p}<0.05)$. Under second load intervals PQ $(t=2.97, \mathrm{p}<0.05)$ and $\mathrm{QT}(\mathrm{t}=5.51, \mathrm{p}<0.05)$ reduced with simultaneous increase of QRS complex $(\mathrm{t}=-$ $2.10, p<0.05)$. The first minute of relaxation resulted in opposite dynamic of the mentioned intervals. In second minute of relaxation this tendency remained: interval QT was still less than initial. By the end of the last minute of relaxation in group 2 there were no significant differences between ECG intervals and initial levels and previous stage.

Results of ECG teeth analysis are presented in table 3.

Analysis of differences between groups was fulfilled with the help of parametric and non parametric criteria. We found that in group 1 before load tooth $\mathrm{R}$ was higher $(\mathrm{U}=16, \mathrm{p}<0.05)$.

After first stage of load in group 1 tooth $\mathrm{Q}(\mathrm{U}=16$, $\mathrm{p}<0.05)$ and tooth $\mathrm{R}(\mathrm{U}=14, \mathrm{p}<0.05)$ amplitudes were

Table 2. Electric cardio gram's intervals of kick boxers under load and in recreation (msec.)

\begin{tabular}{lllllllll}
\hline & 1 group & & & \multicolumn{3}{c}{ 2 group } & & \\
& P & PQ & QRS & QT & P & PQ & QRS & QT \\
\hline \multirow{2}{*}{ Before load } & 79.44 & 118.22 & 96.78 & 352.78 & 82.25 & 137.88 & 90.50 & 344.38 \\
& \pm 9.15 & \pm 15.53 & \pm 3.45 & \pm 17.95 & \pm 12.21 & \pm 17.35 & \pm 5.13 & \pm 8.46 \\
1 stage & 63.00 & 84.89 & 103.89 & $284.89^{1}$ & 68.88 & 104.25 & 103.13 & 285.13 \\
& \pm 11.57 & \pm 13.17 & \pm 2.86 & \pm 6.22 & \pm 12.08 & \pm 13.37 & \pm 11.52 & $\pm 8.62^{1}$ \\
2 stage & 55.44 & 84.67 & 92.56 & $269.56^{2}$ & 64.63 & 74.75 & 109.75 & 271.25 \\
& \pm 9.40 & \pm 10.38 & \pm 6.34 & \pm 13.28 & \pm 7.54 & $\pm 12.86^{2}$ & $\pm 7.57^{2}$ & $\pm 10.22^{2}$ \\
1 minute & 70.67 & 108.78 & 90.78 & $288.78^{2}$ & 73.71 & 124.86 & 88.71 & 287.86 \\
& \pm 6.52 & \pm 9.14 & \pm 4.77 & \pm 11.18 & \pm 8.35 & $\pm 16.14^{1}$ & $\pm 5.92^{1}$ & $\pm 11.54^{2}$ \\
2 minute & 70.75 & 100.50 & 102.75 & 306.63 & 81.00 & 120.50 & 87.00 & 313.50 \\
& \pm 9.60 & \pm 14.28 & \pm 8.05 & \pm 24.05 & \pm 7.20 & \pm 15.76 & \pm 29.79 & $\pm 9.64^{2}$ \\
3 minute & 57.38 & 93.88 & 92.50 & $280.50^{2}$ & 84.67 & 135.33 & 94.33 & 261.00 \\
& \pm 9.75 & \pm 15.33 & \pm 6.45 & \pm 30.42 & \pm 14.44 & \pm 24.63 & \pm 11.29 & \pm 69.35 \\
\hline
\end{tabular}

Note: 1 - difference from previous stage is confident $(p<0.05) .3$ - difference from initial level is confident $(p<0.05)$. 
Table 3. ECG teeth of kick boxers under load and in recreation ( $\mathrm{mV}$ )

\begin{tabular}{|c|c|c|c|c|c|c|c|c|c|c|}
\hline & \multicolumn{5}{|l|}{1 group } & \multicolumn{5}{|l|}{2 group } \\
\hline & $\mathbf{P}$ & $\mathbf{Q}$ & $\mathbf{R}$ & $S$ & $\mathbf{T}$ & $\mathbf{P}$ & $\mathbf{Q}$ & $\mathbf{R}$ & $S$ & $\mathbf{T}$ \\
\hline $\begin{array}{l}\text { Before } \\
\text { load }\end{array}$ & $\begin{array}{l}0.096 \\
\pm 0.056\end{array}$ & $\begin{array}{l}-0.009 \\
\pm 0.012\end{array}$ & $\begin{array}{l}0.419 \\
\pm 0.111\end{array}$ & $\begin{array}{l}-0.032 \\
\pm 0.068\end{array}$ & $\begin{array}{l}0.241 \\
\pm 0.107\end{array}$ & $\begin{array}{l}0.026 \\
\pm 0.013\end{array}$ & $\begin{array}{l}-0.001 \\
\pm 0.002\end{array}$ & $\begin{array}{l}0.177 \\
\pm 0.046\end{array}$ & $\begin{array}{l}-0.119 \\
\pm 0.024\end{array}$ & $\begin{array}{l}0.117 \\
\pm 0.044\end{array}$ \\
\hline 1 stage & $\begin{array}{l}0.030 \\
\pm 0.007\end{array}$ & $\begin{array}{l}-0.021 \\
\pm 0.006\end{array}$ & $\begin{array}{l}0.220 \\
\pm 0.038\end{array}$ & $\begin{array}{l}-0.070 \\
\pm 0.015\end{array}$ & $\begin{array}{l}0.081 \\
\pm 0.021\end{array}$ & $\begin{array}{l}-0.030 \\
\pm 0.072\end{array}$ & $\begin{array}{l}-0.003 \\
\pm 0.008\end{array}$ & $\begin{array}{l}0.133 \\
\pm 0.035\end{array}$ & $\begin{array}{l}-0.094 \\
\pm 0.020\end{array}$ & $\begin{array}{l}0.082 \\
\pm 0.038\end{array}$ \\
\hline 2 stage & $\begin{array}{l}0.046 \\
\pm 0.036\end{array}$ & $\begin{array}{l}-0.026 \\
\pm 0.020\end{array}$ & $\begin{array}{l}0.230 \\
\pm 0.061\end{array}$ & $\begin{array}{l}-0.087 \\
\pm 0.028\end{array}$ & $\begin{array}{l}0.070 \\
\pm 0.038\end{array}$ & $\begin{array}{l}0.006 \\
\pm 0.016\end{array}$ & $\begin{array}{l}0.005 \\
\pm 0.003\end{array}$ & $\begin{array}{l}0.093 \\
\pm 0.017\end{array}$ & $\begin{array}{l}-0.070 \\
\pm 0.014\end{array}$ & $\begin{array}{l}0.042 \\
\pm 0.041\end{array}$ \\
\hline 1 minute & $\begin{array}{l}0.035 \\
\pm 0.007\end{array}$ & $\begin{array}{l}0.001 \\
\pm 0.010\end{array}$ & $\begin{array}{l}0.263 \\
\pm 0.048\end{array}$ & $\begin{array}{l}-0.107 \\
\pm 0.025\end{array}$ & $\begin{array}{l}0.127 \\
\pm 0.018\end{array}$ & $\begin{array}{l}0.031 \\
\pm 0.007\end{array}$ & $\begin{array}{l}-0.005 \\
\pm 0.011\end{array}$ & $\begin{array}{l}0.114 \\
\pm 0.046\end{array}$ & $\begin{array}{l}-0.152 \\
\pm 0.034^{2}\end{array}$ & $\begin{array}{l}0.096 \\
\pm 0.046\end{array}$ \\
\hline 2 minute & $\begin{array}{l}0.031 \\
\pm 0.009\end{array}$ & $\begin{array}{l}-0.006 \\
\pm 0.007\end{array}$ & $\begin{array}{l}0.213 \\
\pm 0.043^{1}\end{array}$ & $\begin{array}{l}-0.100 \\
\pm 0.032\end{array}$ & $\begin{array}{l}0.093 \\
\pm 0.023\end{array}$ & $\begin{array}{l}0.039 \\
\pm 0.007\end{array}$ & $\begin{array}{l}0.001 \\
\pm 0.002\end{array}$ & $\begin{array}{l}0.098 \\
\pm 0.028\end{array}$ & $\begin{array}{l}-0.175 \\
\pm 0.049\end{array}$ & $\begin{array}{l}0.120 \\
\pm 0.049\end{array}$ \\
\hline 3 minute & $\begin{array}{l}0.044 \\
\pm 0.004\end{array}$ & $\begin{array}{l}-0.003 \\
\pm 0.009\end{array}$ & $\begin{array}{l}0.291 \\
\pm 0.065^{1}\end{array}$ & $\begin{array}{l}-0.085 \\
\pm 0.034\end{array}$ & $\begin{array}{l}0.127 \\
\pm 0.021\end{array}$ & $\begin{array}{l}0.046 \\
\pm 0.006\end{array}$ & $\begin{array}{l}0.009 \\
\pm 0.009\end{array}$ & $\begin{array}{l}0.150 \\
\pm 0.027\end{array}$ & $\begin{array}{l}-0.154 \\
\pm 0.078\end{array}$ & $\begin{array}{l}0.134 \\
\pm 0.030\end{array}$ \\
\hline
\end{tabular}

Note: 1 - difference from group 2 is confident $(p<0.05) .2$ - difference from previous stage is confident $(p<0.05)$.

higher. After $2^{\text {nd }}$ stage of load we did not find significant differences between teeth values in different groups.

Recreation period was also characterized by differences between groups. After $1^{\text {st }}$ minute of relaxation in group 1 tooth $\mathrm{P}(\mathrm{r}=4, \mathrm{p}<0.05)$ and tooth $\mathrm{R}(\mathrm{U}=9$, $\mathrm{p}<0.05)$ were higher.

Further, this tendency remained. It was proved by parametric and non parametric criteria. Tooth $\mathrm{R}$ was higher in group 1 after $2^{\text {nd }}$ group of rest $(U=5, p<0.05$, $\mathrm{t}=2.23, \mathrm{p}<0.05)$. The same result was also after $3^{\text {rd }}$ minute of rest $(U=3, p<0.05, \mathrm{t}=2.01, \mathrm{p}<0.05)$.

\section{Discussion}

In scientific researches rather widely the following methodological scheme is used: division of participants, depending on sportsmanship or type of cardio-vascular system's reaction to load. Iakimova E.A. [17] studied interconnection of cardio-vascular system's functional state and physical workability of athletes with different level of workability.

Analysis of morphological functional indicators of arm wrestling athletes of different sportsmanship permitted to substantiate and work our methodic of successfulness prediction in this kind of sports [18, 19].

Choice of cardio-vascular system as the object of study was conditioned by its role in ensuring athletes' adaptation potential and rather high load on it in training and competition processes. Cantero Ivo et al. [20] assessed dynamic of muay tai athletes' physiological parameters during competitions. High load on cardio-vascular system was found independent on results of duels.

Ozemek Cemal et al. [21] used results of tests for load for assessment of this system's state. They confirmed possibility to predict health condition by HBR indicators.

The used methodic scheme of the research permits to assess tolerance to loads and specificities of recreation in athletes. The same results were received by Kiprych S.V. [22]. This author studied reaction to load of boxers' cardio-vascular systems. It was noted that combined assessment of heart rhythm and breathing permits to assess the following: functional ensuring of workability, degree of functions' mobilization in training process; activation of recreation in after-load period.

The absence of significance differences between values of work in testing permits to regard athletes' state as similar. The found differences between cardio-vascular system's indicators are resulted from the applied design of the researches. Division of participants by character of reaction to physical load implies assessment of just these parameters' dynamic.

Analogous results were received in other kinds of sports. Zunzer Stefan C. et al. [23] used cardio-vascular parameters for estimation of loads and energy losses in golf. They proved informative value of HBR monitoring and calculation of metabolic equivalents for assessment of athletes' functional state.

Fernandez-Villarino María A. et al. [24] used cardiovascular parameters for assessments of adaptation to loads and successfulness prognostication in calisthenics. They confirmed connection between HBR and successfulness of performances.

Confidence of differences by HBR indicators on all stages of the research in both groups confirms sufficient athletes' adaptation to physical load. It helps to prevent from pre-nosological health disorders. The registered HBR reduction under load in $1^{\text {st }}$ group athletes can be a proof of higher adaptation mechanisms' level.

Specificities of martial arts pre conditioned peculiarities of all athletes' reaction to loads. $1^{\text {st }}$ group athletes, mainly, react to load by changing of SBP parameters. In group 2 this parameter noticeably changed only on $2^{\text {nd }}$ stage of load. More noticeably DBP parameters changed. In our opinion it reflects unfavorable reaction to loads of cyclic kinds of sports athletes (athletes, who do not train specially for this purpose).

Indicators' changes in recreation period confirm the 
made assumptions. In group 1 BP parameters restored quicker than in group 2. It was confirmed by parametric and non parametric criteria. It permits to speak about quicker stabilization of indicators in athletes with normotonic type of reaction to load.

The received results still more confirm importance of HBR and BP control in athletes. They permit to recommend them for functional state monitoring.

Application of ECG methods in sports is also widely spread. Zemcovskij E.V. [25] analyze ECG in athletes of cyclic kinds of sports. For not cyclic kinds of sports there are much less results. Assessment of any ECG changes only by indicators, registered in state of rest, is insufficient for determination of myocardium functional state. That is why it is possible to judge about myocardium adaptation to physical load only basing on ECG, recorded just in the process of loading.

Lord Rachel et al. [26] used ECG method for estimation of super marathon runners' state. After passing distance the most informative were changes of teeth $\mathrm{P}$ and $\mathrm{R}$, as well as segment ST. The received results are interpreted as illustration of adaptation to load of right half of heart.

Wegmann M. et al. [27] used ECG method for estimation of risks of cardio-vascular system's disorders in football players-veterans. They confirmed effectiveness and informative value of this method in monitoring of athletes' functional state.

The found ECG differences are one more proof of better myocardium state in $1^{\text {st }}$ group athletes. Reduced value of ECG main intervals shall be regarded as witness of better myocardium tonus of athletes with normotonic type of reaction to load.

The registered shortening of QRS intervals after $2^{\text {nd }}$ stage of load reflects the process of ventricles' depolarization.

Less value of PQ interval in recreation period in $1^{\text {st }}$ group can be assessed in two ways. On the one hand it confirms the absence of atrium-ventricular conductivity. Besides, it can be regarded as better adaptation of $1^{\text {st }}$ group athletes' to loads.

Less value of $\mathrm{P}$ interval at the end of recreation period shall be interpreted as witness of normalization of atrium activity, excitation of which is reflected by this period of ECG.

Shortening of ventricular systole in $1^{\text {st }}$ group is illustrated by reduction of QT interval. In our opinion it reflects higher power of myocardium in this group athletes and possibility of more efficient adaptation to loads. Dynamic of this interval in recreation period also testifies in favor of this assumption.

In group 2 first load also resulted in shortening of ventricular systole. It permits to consider it feasible for athletes. Further increase of load caused significant changes of ECG. Besides shortening of ventricular systole, the time of atrium excitation (increase of QRS complex) also happened. It permits to consider the load to be more expressed; to assume transition from adaptation changes to adaptation-compensatory mechanisms.

Absence of expressed ECG changes witnesses about state of adaptation to physical loads. The same results were received in other works. For example Kazuto Omiya et al. [28] studied dynamic and dispersion of QT intervals in athletes of different kinds of sports and in people not sportsmen. No statistically significant differences were found between men and women. Duration of QT interval in martial arts representatives (Judo, fencing) was comparable with results, given in table 2.

Kakhabrishvili Z. et al. [29] studied influence of durable intensive physical loads on cardio-vascular system of elite wrestlers and football players. ECG parameters proved the presence of left ventricular hypertrophy. These indicators correlated with physiological parameters, which reflect tolerance to loads.

Rising of teeth's P, R and Q voltage in group 1 under load and in recreation period confirms ventricular hypertrophy. It is a proof of $1^{\text {st }}$ group athletes' better adaptation to physical loads. The received results in general coincide with other data [25] about ECG in athletes. The author underlines that characteristic features has athletes' cardiogram in trainings for endurance. In non cyclic kinds of sports these properties are less expressed and conditioned by organization of training process.

\section{Conclusions}

The conducted research found certain differences between adaptation potentials of kick boxers' cardiovascular system under standard physical load and in recreation period. We confirmed similarity of reaction to athletes' physical load. Confidentiality of HBR indicators differences on all stages of researches in both groups proves sufficient adaptation potential of athletes. The registered reduction HBR under load in $1^{\text {st }}$ group proves better adaptation mechanisms. Reaction of participants to load reflect specific of martial arts. In recreation period, in group 1 VP parameters recreated quicker than in group 2. It reflects better functional state of these athletes.

The found ECG differences under load and in recreation period also prove better state of $1^{\text {st }}$ group athletes' myocardium. They characterize greater power of myocardium power in this group, possibility of more efficient adaptation to loads. High potential of adaptation mechanisms and functional state of physiological sport heart shall be regarded as long-term adaptation reaction. Trainings of kick boxers with periodic ECG control under loads permits to assess the following: functional state of cardio-vascular system; its adaptation and correspondence to certain physical loads. It permits not to admit pathologies in cardio-vascular system.

\section{Conflict of interests}

The authors declare that there is no conflict of interests. 


\section{References}

1. Durkalec-Michalski K, Podgorski T, Sokolowski M, Jeszka J. Relationship between body composition indicators and physical capacity of the combat sports athletes. Archives of Budo, 2016; 12: 247-256.

2. Jafari RA, Damirchi A, Mirzaei B, Nobari $H$. Anthropometrical profile and bio-motor abilities of young elite wrestlers. Physical education of students, 2016; 20(6): 63-69. doi:10.15561/20755279.2016.0608

3. Mirzaei B, Rahmani-Nia F, Lotfi N, Nabati SM. Trainability of body composition, aerobic power and muscular endurance of cadet wrestlers. Pedagogics, psychology, medicalbiological problems of physical training and sports, 2016; 20(5): 53-57. doi:10.15561/18189172.2016.0508

4. Podrigalo LV, Iermakov SS, Alekseev AF, Rovnaya OA. Studying of interconnectios of morphological functional indicators of students, who practice martial arts. Physical education of students, 2016; 20(1): 64-70. doi:10.15561/20755279.2016.0109

5. Korobeynikov GV, Myshko VV. Connection of supreme nervous functioning's neuro-dynamic characteristics with success of junior sportsmen in sports dances. Pedagogics, psychology, medical-biological problems of physical training and sports, 2016; 20(4): 17-22. doi:10.15561/18189172.2016.0403

6. Bakhareva AS, Isaev AP, Erlikh VV, Aminov AS. Effective long term adaptation and metabolic state regulation of ski-racers. Pedagogics, psychology, medical-biological problems of physical training and sports, 2016; 20(3): 4-10. doi:10.15561/18189172.2016.0301

7. Podrigalo LV, Volodchenko AA. Comparative analysis of bio-mechanical aspects of kick boxing and other martial arts. Visnik Chernigivs'kogo nacional'nogo pedagogichnogo universitetu, 2016; 139(1): 145 - 149. (in Ukrainian)

8. Pryshva OB. Peculiar features of men physical condition in planning highly intensive physical loads in winter period. Pedagogics, psychology, medical-biological problems of physical training and sports, 2016; 20(2): 46-51. doi:10.15561/18189172.2016.0207

9. Iermakov SS, Arziutov GN, Jagiello W. Quick training of students to judo techniques. Archives of Budo. 2016;12:1524.

10.Iermakov SS, Podrigalo LV, Jagiello W. Hand-grip strength as an indicator for predicting the success in martial arts athletes. Archives of Budo. 2016;12:179-86.

11.Allen Mark S., Frings Daniel \& Hunter Steve. Personality, coping, and challenge and threat states in athletes. International Journal of Sport and Exercise Psychology, 2012; 10(4): 264-275. doi:10.1080/1612197X.2012.682375.

12.Drogomeretsky VV, Kopeikina EN, Kondakov VL, Iermakov SS. Adaptation of Ruffier's test for assessment of heart workability of students with health problems. Pedagogics, psychology, medical-biological problems of physical training and sports, 2017; 21(1): 4-10. doi:10.15561/18189172.2017.0101

13.Osipov AY, Kudryavtsev MD, Iermakov SS , Jagiello W. Topics of doctoral and postdoctoral dissertations devoted to judo in period 2000-2016 - the overall analysis of works of Russian experts. Arch Budo, 2017; 13: 1-10

14.Kotenko KV, Korchazhkina NB, Mikhajlova AA, Petrova MS. Special aspects of modern methodic of athletes' functional testing. Funkcional'naia diagnostika, 2011; 3: 98102. (in Russian)

15.Pankova NB, Bogdanova EV, Liubina BG, Karganov MIu. Monitoring of functional reserves of cardio-vascular system of junior figure skaters by spiro-arterio-cardiorhythmography. Valeologiia, 2014; 1: 51-58. (in Russian)

16.Perkhurov AM. Opportunities of electric cardiography testing of athletes for assessment of cardio-vascular system's state for prediction. Sportivnaia medicina: nauka i praktika, 2013; 3: 40-45. (in Russian)

17.Iakimova EA. Influence of cardio-vascular system's functional state on athletes' physical workability. Vestnik Nauki i Tvorchestva, 2016; 7 (7): 344-351. (in Russian)

18.Podrigalo LV, Galashko M N, Iermakov SS, Rovnaya OA, Bulashev AY. Prognostication of successfulness in armwrestling on the base of morphological functional indicators' analysis. Physical education of students, 2017; 21(1): 46-51. doi:10.15561/20755279.2017.0108

19.Podrigalo LV, Iermakov SS, Jagiełło W. Special indices of body composition as a criterion of somatic development of martial arts practitioners. Arch Budo Sci Martial Art Extreme Sport, 2017; 13: 5-12.

20.Cantero Ivo, Pierantozzi Emanuela, Tam Henry, Tocco Philip, Angius Luca, Milia Raffaele. Physiological responses and match analysis of Muay Thai fighting. International Journal of Performance Analysis in Sport, 2012; 12(3): 507-516.

21.Ozemek Cemal, Whaley Mitchell H, Finch W Holmes, Kaminsky Leonard A. Maximal heart rate declines linearly with age independent of cardiorespiratory fitness levels. European Journal of Sport Science, 2017; 17(5): 563-570. doi:10.1080/17461391.2016.1275042

22.Kiprych SV. Control system improvement of qualified boxers based assessment system change reaction cardiorespiratory during the immediate preparation for competition. Physical education of students, 2014; 4: 26-31. doi:10.6084/ m9.figshare.996011

23.Zunzer Stefan C, von Duvillard Serge P, Tschakert Gerhard, Mangus Brent, Hofmann Peter. Energy expenditure and sex differences of golf playing. Journal of Sports Sciences, 2013; 31, 10, 1045-1053. doi:10.1080/02640414.2013.764465

24.Fernandez-Villarino María A, Sierra-Palmeiro Elena, BoboArce Marta, Lago-Peñas Carlos. Analysis of the training load during the competitive period in individual rhythmic gymnastics. International Journal of Performance Analysis in Sport, 2015; 15(2): 660-667.

25.Zemcovskij EV. Sport cardiology. Sankt Petersburg: Hippocrates; 1995. (in Russian)

26.Lord Rachel, George Keith, Somauroo John, Nikhil Jain, Reese Kristin, Hoffman Martin D. Exploratory insights from the right-sided electrocardiogram following prolonged endurance exercise. European Journal of Sport Science, 2016; 16(8): 1014-1022. doi:10.1080/17461391.2016.1165 292

27.Wegmann M, Steffen A, Pütz K, Würtz N, Such U, Faude O. Cardiovascular risk and fitness in veteran football players. Journal of Sports Sciences, 2016; 34, 6, 576-583. doi:10.108 $0 / 02640414.2015 .1118525$

28.Kazuto Omiya, Hiromitsu Sekizuka, Keisuke Kida, Kengo Suzuki, Yoshihiro J Akashi, Haruo Ohba. Influence of gender and types of sports training on QT variables in young elite athletes. European Journal of Sport Science, 2014; 14(1): S32-S38. doi:10.1080/17461391.2011.641032

29.KakhabrishviliZ, Akhalkatsi V, Maskhulia L \& Chutkerashvili T. Hypertrophy of the left ventricle of the heart of Georgian wrestlers and football players of high qualification due to intense physical stress: link with the aerobic capacity. International Journal of Wrestling Science, 2011; 1(1): 4854. doi:10.1080/21615667.2011.10878919 


\section{Information about the authors:}

Podrigalo L.V.; http://orcid.org/0000-0002-7893-524X; I.podrigalo@mail.ru; Kharkov State Academy of Physical Culture; Klochkovskaya str. 99, Kharkov, 61022, Ukraine.

Volodchenko A.A.; http://orcid.org/0000-0002-1189-3524; volodchenko_aa@mail.ru; Kharkov State Academy of Physical Culture; Klochkovskaya str. 99, Kharkov, 61022, Ukraine.

Rovnaya O.A.; http://orcid.org/0000-0003-1519-5632; rovnayaolga@mail.ru; Kharkov State Academy of Physical Culture; Klochkovskaya str. 99, Kharkov, 61022, Ukraine.

Ruban L.A.; http://orcid.org/0000-0002-7192-0694; slarisaruban@gmail.com; Kharkov State Academy of Physical Culture; Klochkovskaya str. 99, Kharkov, 61022, Ukraine.

Sokol K.M.; http://orcid.org/0000-0001-8363-8402; sokolvk@ukr.net; Kharkov National Medical University; 4 Nauky Avenue, 61022, Kharkov, Ukraine.

Cite this article as: Podrigalo LV, Volodchenko AA, Rovnaya OA, Ruban LA, Sokol KM. Analysis of adaptation potentials of kick boxers' cardio-vascular system. Pedagogics, psychology, medical-biological problems of physical training and sports, 2017;21(4):185-191. doi:10.15561/18189172.2017.0407

The electronic version of this article is the complete one and can be found online at: http://www.sportpedagogy.org.ua/index.php/PPS/issue/archive

This is an Open Access article distributed under the terms of the Creative Commons Attribution License, which permits unrestricted use, distribution, and reproduction in any medium, provided the original work is properly cited (http://creativecommons.org/licenses/by/4.0/deed.en).

Received: 04.05.2017

Accepted: 15.05.2017; Published: 30.08 .2017 